
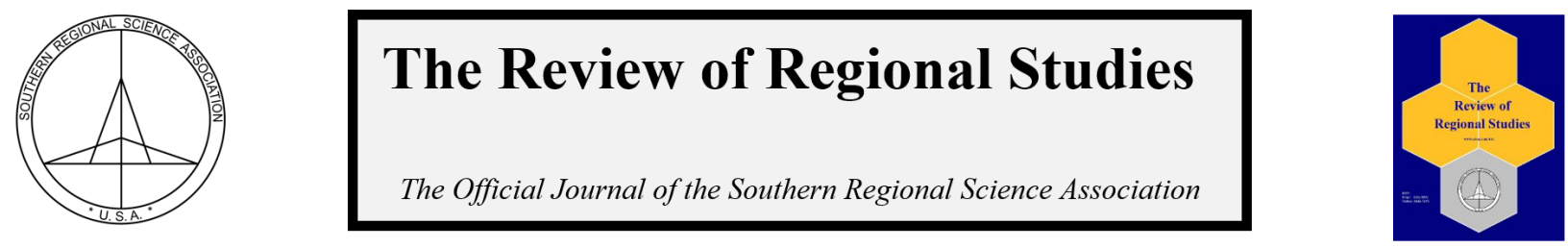

\title{
A Role for Regional Science in Analyzing Water Issues *
}

\author{
Christa D. Court ${ }^{\mathrm{a}}$ and Elham Erfanian ${ }^{\mathrm{b}}$ \\ ${ }^{a}$ Food and Resource Economics Department, University of Florida, USA \\ ${ }^{b}$ Regional Research Institute, West Virginia University, USA
}

\begin{abstract}
The World Economic Forum has consistently ranked water crises as one of the top five most impactful issues facing humanity, alongside but not completely separate from issues such as climate change and natural disasters (World Economic Forum, 2019). A growing population and changing climate will only further stress the constrained water system. Acute and ongoing societal disruptions, caused by significant declines in the available quality and quantity of fresh water around the globe, underscore the importance of water to human life and a functional society. The papers in this special issue highlight the role that regional scientists can and should play in informed decision-making related to water at the local, regional, and national scale.
\end{abstract}

Keywords: water, regional science, integrated analysis, open science

JEL Codes: Y2, Q25, R1

Access to water is necessary for the survival of human, animal, and most plant species. Due to the coupled nature of human and natural systems, economic prosperity, quality of life, and the environment are all inextricably linked by water. Availability, quality, and use of water are regional by nature and though interregional trade in water is possible, regional variations in natural and historical resource allocations will continue to play roles in regional development and will likely become more important over time. Absent improvements in water management and efficiency improvements related to water use, additional stress on water resources might lead to reduced economic development potential (even the possibility of negative growth), poorer quality of life, and environmental hazards. The interdisciplinary field of regional science - with its focus on the important roles of local and regional processes to socioeconomic performance and sustainability, its explicit treatment of spatial relationships, and its increasing attention devoted to modeling the linkages between the human system and the environment - is ideally suited to contribute high quality, policy relevant research on water.

\footnotetext{
${ }^{*}$ Court is an Assistant Professor and Director of the Economic Impact Analysis Program in the Food and Resource Economics Department at the University of Florida. Erfanian is a Graduate Research Assistant in the Regional Research Institute at West Virginia University. The authors acknowledge helpful comments and discussion from session participants in special sessions on Water and Regional Science at the $6^{\text {th }}$ Biennial University of Florida Water Institute Symposium and the $57^{\text {th }}$ Annual Meeting of the Southern Regional Science Association. Corresponding Author: C.D. Court, E-mail: ccourt@ufl.edu
} 
Regional scientists have qualitatively and quantitively examined water-related issues as early as the 1960s and 1970s (Conley, 1967; Shapiro, 1969; Martin and Young, 1969; Davis, 1969; Eggleston and Henry, 1978). In the 1980s, regional scientists largely focused on a broad set of issues related to efficiency of water provision and ownership including water rights (Snyder and Andersen, 1988), economy of scale and economy of scope in water supply (Kim and Clark, 1988), alternative assessment for the value of water (Lichty and Anderson, 1985), and water opportunity costs (Gale and Merz, 1985). Later studies focused on measuring the economic impacts of water reallocation and water policies using a range of techniques such as demand and cost functions (Bhattacharyya et al., 1995; Burton, 1995) and computable general equilibrium modeling (Seung et al., 1998, 1999).

In more recent years, regional scientists have broadened the methods of analysis for analyzing regional water issues as well as water supply, demand, and pricing, including hedonic models (Chamblee et al., 2009; Suparman et al., 2016), cost functions (Bottasso and Conti, 2009), price elasticities (Duke et al., 2002), constructing composite indeces (Nissan and Carter, 2002), demand functions (Bae, 2007), input-output analysis (Whited, 2010; Guerrero et al., 2017; Dudesing, 2017), social accounting matrices and regional computable general equilibrium models (Seung et al., 2000), sequential and bilateral trading algorithms (Smith et al., 2012), quasi-experimental control group analysis (Golden and Leatherman, 2019), surveys (Greenhalgh and Selman, 2012; Hartt, 2014; Thaler, 2016), and monocentric city and polycentric city models (Legras, 2015).

Within the last decade, several prominent regional scientists have highlighted the unique role that regional science can play in providing policy relevant, geographically specific information to decisionmakers (Lahr, 2009; Connaughton, 2010; Jackson et al., 2012; Woodward, 2012; White, 2012) and have called for regional scientists to continue to engage in interdisciplinary research endeavors of human-environment interactions in collaboration with colleagues from other disciplines (Batabyal and Nijkamp, 2003). The papers in this special issue demonstrate how classic topics in regional science, including theoretical economic geography, econometric analysis, and input-output analysis, can be useful to public and private decisionmaking processes in regions currently struggling with water-related issues or preparing for potential future water crises, complementing the work from physical science, engineering, and design disciplines that focus on important geological, hydrological, and environmental considerations.

The issue begins with a piece by Juan Carlos G. Lopez that uses a theoretical economic geography approach to determine how the uneven distribution of water resources and differences in trade regimes for interbasin water transfers can impact land use, particularly the location and distribution of urban and agricultural uses. Several scenarios and trade regimes are analyzed allowing for the graphical display of the impact of the parameters on land use patterns, population size and regional prices. Lopez also provides an application that is calibrated to stylized facts of California.

Following that article is a piece by Gregory Krohn that uses econometric analysis and data on household water consumption to measure the effectiveness of non-price policies (e.g. water use restrictions) during a moderate drought event in the State of Pennsylvania that occurred between 2015 and 2017. He finds that voluntary water use restrictions have smaller than desired effects and that the effects are larger the higher the marginal price 
of water, perhaps reflecting a trade-off between non-monetary benefits and the welfare loss from reducing water usage.

Next, a piece by Xiang Bi, Tatiana Borisova, and Alan W. Hodges contributes to the debate surrounding the restoration of the natural flow of Florida's Ocklawaha River, which is currently impounded by a dam that was part of an abandoned cross-Florida barge canal project. They use a survey methodology and economic contribution analysis to assess the trade-offs of dam removal by estimating the economic benefits and regional economic contribution of recreation at the reservoir and the upstream free-flowing river. Results suggest that river-based recreation generates greater benefits and contributions than the reservoir and that the loss in economic value for reservoir-related recreation can potentially be mitigated.

The next four pieces highlight the usefulness of integrated environment-economic modeling, each using an approach based on environmentally extended input-output modeling applied to different regions of the world and to answer slightly different research questions.

The first piece by Oluwafisayo Alabi, Max Munday, Kim Swales, and Karen Turner uses a single-region environmentally extended input-output model to analyze the total physical demand for water in Wales, United Kingdom. They extend a framework that is typically used to account for the production of polluting outputs to instead account for natural resource inputs, specifically public water use and supply. This analysis shows that by using both the quantity input-output model and the associated price dual, economy-wide implications of the deviation between expenditures on the output of the water sector and actual physical water supplied can be investigated.

Next, two pieces investigate the use of environmentally extended multi-regional inputoutput analysis to identify measures akin to water footprints. The first, by Di Sheng, Stephanie Owen, Dayton M. Lambert, Burton C. English, Robert J. Menard, David W. Hughes, Lixia He-Lambert, and Christopher D. Clark, investigates water-use in the Southeastern United States and finds heterogeneous total water withdrawals across industries within the region. The second piece by Jaqueline Coelho Visentin and Joaquim José Martins Guilhoto uses a similar methodology to investigate the role of uneven spatial distribution of water resources and interregional trade on the virtual blue water footprint in Brazil. They find that virtual blue water flows are largely interregional and that a majority of the flows in Brazil are exports from basins where the water balance indicates potential water scarcity, suggesting that interregional trade in virtual blue water potentially undermines regional water security. Both pieces note the importance of their results for regional water management decisions.

The issue wraps up with a piece by Kevin Credit, Elizabeth Mack, and Sarah Wrase that integrates information on household spending with multi-regional input-output analysis to examine the link between the cost of water and measures of economic vitality. The piece demonstrates a novel methodology to estimate changes in household spending information from the Consumer Expenditure Survey for a particular change in water prices, which are linked to a multi-regional input-output models to estimate the regional economic impacts associated with changes in consumer spending patterns.

Each of the papers in this issue highlights the role that regional scientists can and should

(C)Southern Regional Science Association 2019. 
play in informed decision-making related to water at the local, regional, and national scale and regional scientists are encouraged to expand this role within their own areas of expertise and regions of the world by collaborating with each other and colleagues in other disciplines that are interested in water-related research. As private and public institutions continue to plan for potential changes in the quantity and quality of future water supplies resulting from a changing climate and continued economic development, there will be a continued need for policy relevant and geographically specific research on water supply, water use, trade in water (real and virtual) and the distribution of the natural resource itself.

So, where do we go from here? How should society deal with aging water supply infrastructure? What technologies are available to reduce water consumption of various industry and municipal users and is their use economically feasible? How should a water-scarce region handle population and industrial growth? Will water availability become a significant determinant of human and/or business migration patterns? Will regional specialization eventually be determined by water availability such that water abundant regions specialize in activities that are water intensive (agriculture, thermoelectric power, etc.) or that allow for transfer of water to nearby regions with water scarcity? Will water scarce regions specialize in less water-intensive technologies and make these technologies viable in other regions as cost goes down? What effect will all of this change have on the environment and on water quantity and quality? Regional scientists are poised to answer questions such as these and can also help with assessing the economic and societal impacts of adaptions to a changing climate, which could certainly impact water availability.

Finding answers to these questions will require continued integrated, interdisciplinary efforts to analyze interactions among the natural and human systems and regional scientists are encouraged to participate. Also, it is well known that open science and interdisciplinary research can yield more reliable knowledge, more rapid and creative generation of results, and broader and more inclusive participation in the research process (National Academies of Sciences and Medicine, 2018b). To ensure that regional science research, whether related to water or not, produces actionable and trusted information and also aids in facilitation of larger scale research, research questions should be refined, guided, and vetted through a participatory process with practitioners and community members (National Academies of Sciences and Medicine, 2018a). The papers in this issue highlight the role that regional scientists can and should play in informed decision-making related to water at the local, regional, and national scale and regional scientists are encouraged to expand this role within their own areas of expertise and regions of the world by collaborating with each other and colleagues in other disciplines that are interested in water-related research.

\section{REFERENCES}

Bae, Suho. (2007) "Explaining Geographical Differences in Water Prices: Do Institutional Factors Really Matter?," Review of Regional Studies, 37(2), 207-250.

Batabyal, Amitrajeet. and Nijkamp, P. (2003) "The Environment in Regional Science: An Eclectic Review," Review of Economic Design, 83, 291-316.

Bhattacharyya, Arunava., Harris, Thomas R., Narayanan, Rangesan., and Raffiee, Kam-

(C)Southern Regional Science Association 2019. 
biz. (1995) "Specification and Estimation of the Effect of Ownership on the Economic Efficiency of the Water Utilities," Regional Science and Urban Economics, 25(6), 759-784. Bottasso, Anna. and Conti, Maurizio. (2009) "Scale Economies, Technology and Technical Change in the Water Industry: Evidence from the English Water only Sector," Regional Science and Urban Economics, 39(2), 138-147.

Burton, Mark L. (1995) "Rail Rates and the Availability of Water Transportation: The Missouri Valley Region," Review of Regional Studies, 25(1), 79-95.

Chamblee, John F., Dehring, Carolyn A., and Depken, Craig A. (2009) "Watershed Development Restrictions and Land Prices: Empirical Evidence from Southern Appalachia," Regional Science and Urban Economics, 39(3), 287-296.

Conley, Bryan C. (1967) "Price Elasticity of the Demand for Water in Southern California," The Annals of Regional Science, 1(1), 180-189.

Connaughton, John E.. (2010) "SRSA Presidential Address: Local Economic Impact of the Great Recession of 2008-2009," The Review of Regional Studies, 40(1), 1-4.

Davis, H. C.. (1969) "Water Quality Impact Analysis," The Annals of Regional Science, $3(2), 66-74$.

Dudesing, Rebekka. (2017) "Potential Economic Impacts of Inter-regional Water Sales Under Two Texas Aquifer Scenarios," Journal of Regional Analysis $\&$ Policy, 47(2), 164-175.

Duke, Joshua M., Ehemann, Robert W., and Mackenzie, John. (2002) "The Distributional Effects of Water Quantity Management Strategies: A Spatial Analysis," Review of Regional Studies, 32(1), 19-35.

Eggleston, Brian. and Henry, Mark S. (1978) "Water as a Constraint to Economic Development in Western North Dakota," Journal of Regional Analysis and Policy, 8(1100-201689943), 14-31.

Gale, James R. and Merz, Thomas E. (1985) "The Opportunity Cost of an Abundant Resource: The Case of Water Diverted from the Great Lakes to the Ogallala Aquifer Region," Journal of Regional Analysis and Policy, 15(1100-2016-90049), 3-12.

Golden, Bill B. and Leatherman, John C. (2019) "Impact Analysis of the Walnut Creek Intensive Groundwater Use Control Area," Journal of Regional Analysis 83 Policy, 47(2), 176-187.

Greenhalgh, Suzie. and Selman, Mindy. (2012) "Comparing Water Quality Trading Programs: What Lessons Are There to Learn?," Journal of Regional Analysis and Policy, 42(1100-2016-89913).

Guerrero, Bridget., Amosson, Steve., Nair, Shyam., and Marek, Thomas. (2017) "The Importance of Regional Analysis in Evaluating Agricultural Water Conservation Strategies," Journal of Regional Analysis 85 Policy, 47(2), 188-198.

Hartt, Maxwell Douglas. (2014) "An Innovative Technique for Modelling Impacts of Coastal Storm Damage," Regional Studies, Regional Science, 1(1), 240-247.

Jackson, Randall W., White, Nancy., et al. (2012) "The Role of Regional Science in Shale Energy Development," Review of Regional Studies, 42(2), 99-105.

Kim, H Youn. and Clark, Robert M. (1988) "Economies of Scale and Scope in Water Supply," Regional Science and Urban Economics, 18(4), 479-502.

Lahr, Michael L.. (2009) "Regional Science, Regional Scientists, and State Policy," International Regional Science Review, 32(4), 495-508.

Legras, Sophie. (2015) "Correlated Environmental Impacts of Wastewater Management in

(C)Southern Regional Science Association 2019. 
a Spatial Context," Regional Science and Urban Economics, 52, 83-92.

Lichty, Richard W. and Anderson, Curt L. (1985) "Assessing the Value of Water: Some Alternatives," Journal of Regional Analysis and Policy, 15(2), 39-51.

Martin, William E. and Young, Robert A. (1969) "The Need for Additional Water in the Arid Southwest: An Economist's Dissent," The Annals of Regional Science, 3(1), 22-31.

National Academies of Sciences, Engineering. and Medicine (2018a). Learning Through Citizen Science: Enhancing Opportunities by Design.

National Academies of Sciences, Engineering. and Medicine (2018b). Open Science by Design: Realizing a Vision for 21st Century Research.

Nissan, Edward. and Carter, George. (2002) "Ranking Regional Air and Water Environmental Degradations," Review of Regional Studies, 32(1), 69-85.

Seung, Chang K., Harris, Thomas R., Englin, Jeffrey E., and Netusil, Noelwah R. (1999) "Application of a Computable General Equilibrium (CGE) Model to Evaluate Surface Water Reallocation Policies," Review of Regional Studies, 29(2), 139-155.

Seung, Chang K., Harris, Thomas R., Englin, Jeffrey E., and Netusil, Noelwah R. (2000) "Impacts of Water Reallocation: A Combined Computable General Equilibrium and Recreation Demand Model Approach," The Annals of Regional Science, 34(4), 473-487.

Seung, Chang K., Harris, Thomas R., MacDiarmid, Thomas R., and Shaw, W Douglass. (1998) "Economic Impacts of Water Reallocation: A CGE Analysis for Walker River Basin of Nevada and California," Journal of Regional Analysis and Policy, 28(2), 13-34.

Shapiro, David L. (1969) "Water Rights and Wrongs," The Annals of Regional Science, 3(2), 139-147.

Smith, Craig M., Peterson, Jeffrey M., Leatherman, John C., and Wiliams, Jeffrey R. (2012) "A Simulation of Factors Impeding Water Quality Trading," Journal of Regional Analysis \& Policy, 42(2), 162-176.

Snyder, Donald L. and Andersen, Jay C. (1988) "Competition for Water: The issue of Native American Water Rights," The Annals of Regional Science, 22(1), 54-64.

Suparman, Yusep., Folmer, Henk., and Oud, Johan HL. (2016) "The willingness to Pay for In-house Piped Water in Urban and Rural Indonesia," Papers in Regional Science, 95(2), 407-426.

Thaler, Thomas. (2016) "Moving Away from Local-based Flood Risk Policy in Austria," Regional Studies, Regional Science, 3(1), 329-336.

White, Nancy. (2012) "A Tale of Two Shale Plays," The Review of Regional Studies, 42(2), $107-119$.

Whited, Melissa. (2010) "Economic Impacts of Irrigation Water Transfers on Uvalde County, Texas," Journal of Regional Analysis and Policy, 40(1100-2016-89585).

Woodward, Douglas P.. (2012) "Presidential Address: Industry Location, Economic Development Incentives, and Clusters," The Review of Regional Studies, 42(1), 5-23.

World Economic Forum (2019). Global Risks Report 2019. 